\title{
LAS EUROPEAN RULES OF CIVIL PROCEDURE: ¿UN PUNTO DE PARTIDA PARA LA ARMONIZACIÓN DEL PROCESO CIVIL?*
}

\section{THE EUROPEAN RULES OF CIVIL PROCEDURE: A STARTING POINT FOR CIVIL PROCEDURE HARMONISATION?}

\author{
Fernando Gascón InCHAUsti \\ Catedrático de Derecho Procesal \\ Universidad Complutense de Madrid \\ Instituto de Derecho Europeo e Integración Regional (IDEIR)
}

Recibido: 19.01.2021 / Aceptado: 23.01.2020

DOI: https://doi.org/10.20318/cdt.2021.5960

\begin{abstract}
Resumen: En otoño de 2020 el European Law Institute y UNIDROIT aprobaron las European Rules of Civil Procedure, un conjunto sistemático de normas a través de las que se diseña un modelo de proceso civil con potencial para resultar operativo en cualquier país europeo. Se trata, obviamente, de un instrumento de soft law, que se basa en un extenso y prolongado trabajo de comparación jurídica, que ha permitido detectar las mejores soluciones a las necesidades que suscita hoy en día un sistema de justicia civil eficiente. Se analizan qué son y qué no son las European Rules, al tiempo que se desgranan los rasgos esenciales del modelo procesal civil diseñado, caracterizado por la flexibilidad, la gestión activa del procedimiento y el esfuerzo sostenido por la solución consensual del litigio. Es difícil vaticinar cuál será su impacto futuro, aunque sin duda las European Rules of Civil Procedure están llamadas a desempeñar un papel relevante en cualquier tarea de armonización procesal civil que se emprenda en el futuro, en la medida en que han demostrado que técnicamente resulta posible y que, por tanto, las variables de las que depende son primordialmente políticas.

Palabras clave: European Rules of Civil Procedure, Proyecto ELI/UNIDROIT, reglas modelo, armonización del proceso civil, proceso civil comparado, gestión activa del procedimiento.
\end{abstract}

Abstract: In autumn 2020, the European Law Institute and UNIDROIT approved the European Rules of Civil Procedure, a systematic set of rules through which a civil process model is designed with the potential to be operational in any European country. It is obviously a soft law instrument, which is based on an extensive and prolonged work of legal comparison, which has made it possible to detect the best solutions to the needs of an efficient civil justice system today. This contribution analyses what the European Rules are and what they are not, along with the essential features of the civil procedural model designed, characterized by flexibility, case management and a sustained effort for the consensual solution of the dispute. It is difficult to predict what their future impact will be, although the European Rules of Civil Procedure are certainly called upon to play a relevant role in any task of civil procedural harmonisation that is undertaken in the future, to the extent that they have shown that it is technically possible and that, therefore, that it depends primarily on political variables.

Keywords: European Rules of Civil Procedure, ELI/UNIDROIT Project, model rules, civil procedure harmonisation, comparative civil procedure, case management.

*Este trabajo es uno de los resultados del proyecto de investigación "Hacia un proceso civil convergente con Europa. Hitos presentes y retos futuros" (PGC2018-094693-B-I00), financiado por el Ministerio de Ciencia, Innovación y Universidades. 
Sumario: I. La elaboración de las European Rules of Civil Procedure. II. ¿Son las European Rules of Civil Procedure un código modelo? 1. Las European Rules no pretenden ser un código. 2. Las European Rules of Civil Procedure sí ofrecen un modelo. A) El método y el enfoque seguidos para la elaboración de las European Rules. B) Las European Rules of Civil Procedure están diseñadas de manera sistemática. III. El modelo procesal civil que proponen las European Rules of Civil Procedure. 1. Un modelo de proceso civil flexible, basado en las nociones de cooperación, de proporcionalidad y de gestión activa del procedimiento. A) Flexibilidad procedimental. B) Fomento de la solución consensual de la controversia. C) Proporcionalidad. 2. Una dinámica procedimental clásica. A) Primera instancia. B) Recursos frente a la sentencia. 3. Herramientas accesorias para reforzar el derecho a la tutela judicial efectiva. A) Acceso a información en poder de las demás partes y de terceros. B) Tutela cautelar. C) Tutela colectiva. IV. ¿Perspectivas de futuro?

\section{La elaboración de las European Rules of Civil Procedure}

1. En fechas recientes se ha producido un acontecimiento de especial relevancia en el ámbito jurídico procesal: la aprobación de las European Rules of Civil Procedure (ERCP) por parte del European Law Institute (ELI) y del Instituto Internacional para la Unificación del Derecho Privado (UNIDROIT). ${ }^{1}$ Ambas instituciones han otorgado así su beneplácito al resultado final de un proyecto común que perseguía el objetivo de la elaboración de una suerte de "Código Modelo" para Europa, como forma de concretar y desarrollar para un ámbito regional determinado una propuesta anterior, la de los ALI / UNIDROIT Principles of Transnational Civil Procedure.

2. En 2004, en efecto, UNIDROIT aprobó unos «Principios de proceso civil transnacional», como resultado del trabajo de un equipo conjunto entre el propio UNIDROIT y el American Law Institute (ALI). El objetivo primario de aquel proyecto era ofrecer unos mínimos denominadores comunes que deberían guiar a los legisladores nacionales a la hora de abordar la litigación transnacional: se trataba, en otros términos, de fijarse en las peculiaridades de los procesos transfronterizos y de salvar las diferencias entre las tradiciones procesales nacionales, de modo que fuera más eficaz la coordinación entre sistemas que siempre requiere este tipo de asuntos. Se aspiraba, en definitiva, a reducir la inseguridad jurídica que se cierne sobre los sujetos llamados a litigar en contextos desconocidos.

3. De forma indirecta, los 31 bloques de principios ALI/UNIDROIT se podían considerar también como un intento de ofrecer un armazón o esqueleto básico de lo que podría ser un proceso civil mínimamente armonizado o "modelizado"2: se proponían una serie de elementos o factores comunes a todos los sistemas procesales civiles nacionales -aplicables, al menos, a los litigios transfronterizos, pero extensibles a los puramente internos-, gracias a los cuales resultaría más fácil la comprensión mutua necesaria para facilitar, v.g., la obtención de pruebas en otro Estado, la notificación transfronteriza de demandas o resoluciones y, por supuesto, el reconocimiento y la ejecución de decisiones judiciales extranjeras.

4. Los Principles of Transnational Civil Procedure recibieron en su momento una gran atención en el ámbito académico internacional ${ }^{3}$ y fueron también objeto de discusión y debate en foros profesionales. Su impacto práctico, sin embargo, ha resultado decepcionante: no puede decirse que los legisladores nacionales los hayan tomado como punto de partida o se hayan inspirado abiertamente en ellos a la

${ }^{1}$ El texto puede consultarse en https://www.unidroit.org/instruments/civil-procedure/eli-unidroit-rules. Se puede encontrar ahí el texto bilingüe (inglés y francés) de las reglas y de los comentarios "oficiales" a estas. Se anuncia, no obstante, una versión definitiva y revisada para este año 2021, que publicará Oxford University Press y que estará igualmente accesible en las webs de UNIDROIT y del ELI.

${ }^{2}$ Por seguir la expresión acuñada por F. FERRAND (ed.), La procédure civile mondiale modélisée, Ed. juridiques et techniques, París, 2004.

${ }^{3}$ Así lo demuestra la extensa bibliografía al respecto. Gran parte de la aparecida hasta finales de 2013 ha sido compilada por UNIDROIT, en un listado disponible en https://www.unidroit.org/tcp-bibliography. Para una visión más reciente, cfr. M. Taruffo, "Harmonization in a Global Context: The ALI/Unidroit Principles", en X. E. Kramer / C.H. van Rhee (eds). Civil Litigation in a Globalizing World, Asser Press, La Haya, 2012, pp. 207-219; G. OrmazABAL SÁnchez, La brecha procesal civil entre EEUU y Europa, Tirant lo Blanch, Valencia, 2016, pp. 153 y ss. 
hora de afrontar reformas concretas. Quizá la explicación radique en su carácter demasiado genérico ${ }^{4}-$ necesario para lograr un consenso global entre sistemas diversos- $\mathrm{o}$ en la escasa consideración que suele dedicarse por el legislador a la litigación transfronteriza. Para evitar que el esfuerzo cayera en saco roto, en 2013 UNIDROIT, esta vez de la mano del European Law Institute, concibió un proyecto concebido como secuela de este: se trataba de pasar de los principios globales acuñados en 2004 a la elaboración de reglas más detalladas y pensadas para aplicarse en un contexto regional de mayor integración, el europeo. Así, con la rúbrica "From Transnational Principles to European Rules of Civil Procedure" se celebró un encuentro inicial en Viena en otoño de 2013, que sirvió de plataforma de lanzamiento del nuevo proyecto, que se materializó en 2014, con el acuerdo formal de ambas instituciones para elaborar un conjunto de reglas y preceptos, las European Rules of Civil Procedure. ${ }^{5}$

5. La actividad del proyecto, que ha cubierto un periodo de casi siete años, se ha articulado sobre la base de la constitución de grupos de trabajo temáticos -integrados mayoritariamente por académicos y algunos profesionales del Derecho- vinculados a parcelas diversas del proceso civil, que han ido elaborando sus propuestas articuladas de forma sucesiva. En un primer momento se activaron tres grupos, dedicados a «Acceso a información y prueba», «Notificaciones» y «Medidas provisionales y cautelares». En una segunda etapa se constituyeron dos grupos más, uno sobre «Obligaciones de jueces, abogados y partes» y otro sobre «Litispendencia y cosa juzgada». Posteriormente, cuando ya los tres primeros habían concluido su labor y los dos segundos la tenían muy avanzada, se pusieron en marcha otros cuatro grupos, sobre «Partes» (incluyendo la tutela colectiva), «Resoluciones judiciales», «Régimen de recursos» y «Costas». Un último grupo de trabajo se ocupó de la estructura procedimental y, singularmente, de otorgar coherencia y presentar de forma unificada los resultados de los demás grupos.

6. Desde sus momentos iniciales, UNIDROIT y el ELI han querido ir compartiendo sus progresos con otros actores destacados. Han asumido así el rol de observadores del proyecto un número significativo de organizaciones intergubernamentales ${ }^{6}$, de instituciones europeas ${ }^{7}$, de asociaciones profesionales ${ }^{8}$ y de sociedades científico-académicas ${ }^{9}$. Esto explica que los avances y la evolución de los trabajos hayan ido teniendo repercusiones durante el proceso de su propia elaboración, singularmente en el ámbito de la Unión Europea y, más en concreto, del Parlamento Europeo. Así, a modo de ejem-

\footnotetext{
${ }^{4}$ Los redactores de los Principles elaboraron igualmente una serie de Rules, más detalladas, destinadas a concretar el alcance de aquellos. Las Rules, sin embargo, no fueron nunca aprobadas oficialmente ni por el American Law Institute ni por UNIDROIT, aunque sí que se publicaron junto con los Principles.

${ }^{5}$ Se puede encontrar informar más detallada en las páginas web del European Law Institute (https://www.europeanlawinstitute.eu/projects-publications/completed-projects-old/completed-projects-sync/civil-procedure/) y de UNIDROIT (https:// www.unidroit.org/instruments/civil-procedure/eli-unidroit-rules). En doctrina, cfr. R. STÜRNER, "Principles of European civil procedure or a European model code? Some considerations on the joint ELI-Unidrort project", Uniform Law Review 19 (2014), pp. 322 y ss.; E. SiLVESTRI, "Towards A European Code of Civil Procedure? Recent Initiatives for the Drafting of European Rules of Civil Procedure”, https://www.academia.edu/18086809/Towards_a_European_Code_of_Civil_Procedure (2015); E. Silvestri, "The ELI-UNIDROIT Project: A General Introduction”, en F. GAscón Inchausti / B. Hess (eds.), The Future of the European Law of Civil Procedure. Coordination or Harmonisation?, Intersentia, Cambridge, 2020, pp. 199-204; B Hess, "Unionsrechtliche Synthese: Mindeststandards und Verfahrensgrundsätze im acquis communautaire / Schlussfolgerungen für European Principles of Civil Procedure”, en M. Weller / C. Althammer (eds.), Mindeststandards im europäischen Zivilprozessrecht, Mohr Siebeck, Tubinga, 2015, pp. 221 y ss.; C.H. van RHEe, "Approximation of Civil Procedural Law in the European Union", en B. Hess / X. Kramer (eds.), From common rules to best practices in European Civil Procedure, Nomos-Hart, Baden-Baden, 2017, pp. 63-75; L. Peters, "UNIDROIT. The first 90 years", en A. Calvo Caravaca / I. Tirado Martí (eds.), UNIDROIT y la codificación del Derecho Internacional Privado, Tirant lo Blanch, Valencia, 2020, pp. 19-55; B. Hess, Europäisches Zivilprozessrecht, De Gruyter, Berlín, 2020, pp. 953-956.

${ }^{6}$ La Conferencia de La Haya de Derecho Internacional Privado.

${ }^{7}$ El Parlamento Europeo, la Comisión y el Tribunal de Justicia.

${ }^{8} \mathrm{La}$ Association for International Arbitration (AIA), el Council of Bars and Law Societies of Europe (CCBE), el Council of the Notariats of the European Union (CNUE), la European Network of the Councils of the Judiciary (ENCJ), la International Bar Association (IBA), la Union Internationale des Avocats (UIA), la International Association of Young Lawyers (AIJA) y la Union internationale des huissiers de justice-International Union of Judicial Officers (UIHJ).

${ }^{9}$ El American Law Institute (ALI), la Asociación Americana de Derecho Internacional Privado (ASADIP), la International Association of Procedural Law (IAPL) y el Max Planck Institute Luxembourg for Procedural Law.
} 
plo, el Comité de Asuntos Jurídicos del Parlamento Europeo publicó en enero de 2017 el estudio "The European Law Institute/UNIDROIT Civil Procedure project as a Soft Law Tool to Resolve Conflicts of Law"10, en el que ya se concluía la utilidad del proyecto de cara a la elaboración de una hipotética directiva europea. ${ }^{11}$ Meses después, el 4 de julio de 2017 el Parlamento Europeo adoptó precisamente una resolución con recomendaciones a la Comisión en materia de normas comunes mínimas de proceso civil en la Unión Europea, que incluye una propuesta de directiva sobre normas comunes mínimas ${ }^{12}$ y que alude en su preámbulo al proyecto ELI/UNIDROIT. Muy poco tiempo después de la aprobación de esta resolución -el 12 de julio de 2017-, el Comité de Asuntos Jurídicos del Parlamento Europeo celebró una sesión pública titulada «The ELI- UnIDroIT Civil Procedure Project: State of Play and Next Steps» ${ }^{13}$.

7. Este interés del Parlamento Europeo en el proyecto no debe, sin embargo, llevar a confusión: el carácter «europeo» de las reglas debe entenderse en un sentido amplio, esto es, no restringido a la Unión Europea. Así se explica igualmente la participación en los equipos de trabajo de juristas suizos, noruegos o -de forma sobrevenida- británicos. Es cierto que la actividad normativa de la Unión Europea tiene efectos armonizadores sobre los ordenamientos procesales internos de los Estados miembros ${ }^{14}$ y que, en consecuencia, la integración es mayor entre ellos. Y también lo es que, en gran medida, el proyecto se ha aprovechado del acervo comunitario en materia procesal civil: en ocasiones, las normas comunitarias han inspirado las reglas; en otros casos, su existencia justifica por qué las reglas no han abordado por sí mismas ciertas cuestiones. Pero ha de quedar claro que desde el principio se asumió un enfoque europeo amplio, que, si acaso, debería vincularse con el ámbito de aplicación del Convenio Europeo de Derechos Humanos. Ni el European Law Institute está vinculado de alguna forma a la Unión Europea, ni menos aún puede considerarse que lo esté UNIDROIT.

8. Concluidos los trabajos, el resultado final fue aprobado por el Council del European Law Institute el 15 de julio de 2020 y por el Governing Council de UNIDROIT en su 99a sesión celebrada entre el 23 y el 25 de septiembre de 2020. Se puso con ello fin a un inmenso esfuerzo colectivo, con un enorme potencial para contribuir al desarrollo de los procesos civiles nacionales en el futuro. En relación con esto, es significativo el cambio introducido en la denominación final: European Model Rules of Civil Procedure (según ELI) y ELI/UNIDROIT Model European Rules of Civil Procedure (según UNIDROIT). Con el empleo del término model se asienta sin margen para la duda la naturaleza del producto como Código Modelo y herramienta de soft law. Se trata, evidentemente, de un documento académico-propositivo, no de un texto normativo-vinculante, teniendo en cuenta quién y cómo lo ha elaborado. Pero, al ofrecerse como un sistema articulado de reglas modelo, se hace obvio cuáles eran los objetivos perseguidos. Un análisis más detenido de su contenido nos puede dar la medida de su capacidad para alcanzarlos.

\footnotetext{
${ }^{10}$ Estudio PE 556/972, accesible en https://www.europarl.europa.eu/RegData/etudes/IDAN/2017/556972/IPOL_IDA(2017) 556972_EN.pdf

${ }^{11}$ En concreto, se señala en la p. 14 cómo "[I]n the future, such principles may be used as a basis for an EU directive. A number of challenges will need to be addressed. Once adopted as a soft-law instrument, the 'European Rules of Civil Procedure' could form the basis for the development of a horizontal EU directive, codifying the fundamental principles of civil procedure which, within the realm of the ECHR and the EU Charter, can be considered as striking a fair balance between the rights and interests of both claimants and defendants."

${ }_{12}$ 2015/2084(INL) accesible en http://www.europarl.europa.eu/oeil/popups/ficheprocedure.do?lang=en\&reference=2015/ 2084(INL)). Sobre la propuesta de directiva, con más detenimiento, cfr. F. GaSCón InCHAUSTI, "The 2017 Directive Proposal on Common Minimum Standards of Civil Procedure in the European Union”, en F. Gascón Inchausti / B. Hess (eds.), The Future of the European Law of Civil Procedure. Coordination or Harmonisation?, cit., pp. 241-264 y V. Richard, "The 2017 Proposal of the European Parliament on Common Minimum Standards of Civil Procedure”, en F. Gascón Inchausti, B. Hess (eds.), The Future of the European Law of Civil Procedure. Coordination or Harmonisation?, cit., pp. 265-284.

${ }^{13} \mathrm{Cfr}$. https://www.europarl.europa.eu/cmsdata/123343/juri-committee-hearing-eli-unidroit-programme.pdf

${ }^{14}$ Cfr. F. Gascón Inchausti, "Have the EU Regulations on Judicial Cooperation Fostered Harmonisation of National Procedures?" en F. Gascón Inchausti, B. Hess (eds.), The Future of the European Law of Civil Procedure. Coordination or Harmonisation?, cit., pp. 91-110.
} 


\section{II. ¿Son las European Rules of Civil Procedure un código modelo?}

9. Al proceder a su aprobación definitiva tanto el ELI como UNIDROIT han querido «presentar en sociedad» a las European Rules of Civil Procedure como una suerte de Código Procesal Modelo, en una senda análoga a la abierta hace ya varias décadas por el Instituto Iberoamericano de Derecho Procesal. ${ }^{15}$ Me parece, sin embargo, que definirlas como Código Modelo tampoco resulta suficientemente identificativo de su contenido, pues no existe una noción clara ni comúnmente aceptada de lo que un Código Modelo ha de ser. Veamos, pues, qué hay en ellas de «código» y qué de «modelo».

\section{Las European Rules no pretenden ser un código}

10. Si un código es un conjunto completo y sistemático de normas jurídicas que disciplinan un determinado sector de la realidad, debe asumirse desde el principio que las European Rules of Civil Procedure no superan este filtro en la primera vertiente ("completo"), aunque a mi juicio sí lo hacen en la segunda ("sistemático").

11. Desde luego, el objetivo inicial de pasar de los principios -los 31 Principles of Transnational Civil Procedure- a reglas más concretas y precisas sí que se ha logrado: el proyecto ELI/UNIDROIT ofrece un total de 245 artículos, con sus comentarios, que en la versión provisionalmente publicada en la web de UNIDROIT ocupan más de 500 páginas (en formato espacioso y holgado, eso sí). La cifra de 245 artículos es elevada para un producto de esta envergadura, especialmente si se compara con otros equivalentes elaborados por el propio UNIDROIT y por instituciones equivalentes, como UNCITRAL. Pero es obvio que siguen siendo, al menos en apariencia, pocos preceptos para un código procesal civil al uso: téngase en cuenta que nuestra LEC vigente termina en el artículo 827, aunque tiene más, dados los artículos bis y similares añadidos posteriormente; con iguales añadidos, el code de procédure civile francés termina en el artículo 1582 -aunque es cierto que incluye el arbitraje, los medios alternativos de resolución de controversias y la jurisdicción voluntaria-; el codice di procedura civile italiano concluye en el artículo 840 sexiesdecies; la Zivilprozessordnung alemana llega hasta el parágrafo 1120 -contando también con la regulación del arbitraje y el desarrollo normativo interno de los reglamentos procesales civiles de la UE-; y el más reciente código de processo civil portugués - por cerrar los ejemplos-alcanza la cifra de los 1139 artículos. Evidentemente, no se trata únicamente de una cuestión de cantidad ni de números, sino de contenido. Y ese es el punto en que puede decirse que las European Rules no son un código completo, pues faltan en ellas normas que disciplinen aspectos del proceso civil que cabría esperar en un código. Son varias las omisiones detectables a primera vista: la ejecución forzosa, un sistema de reglas de jurisdicción y competencia, los procesos en materia de derecho de familia y ciertos procesos especiales para lograr el cobro acelerado y/o simplificado de créditos.

12. a) En primer término, no existen propuestas en materia de ejecución forzosa, a pesar de que resulta imprescindible para comprender un sistema de justicia civil. La única excepción es la previsión de una admisión generalizada de la ejecución provisional, que se efectúa en sede de recursos (rule 162) ${ }^{16}$, pero que en realidad nada dice acerca del proceso de ejecución en sí. La razón de esta omisión es puramente pragmática: se trata de una materia demasiado compleja y con una enorme diversidad de partida entre

\footnotetext{
${ }^{15}$ Recuérdese que al Instituto Iberoamericano de Derecho Procesal le corresponde el mérito de haber elaborado tres códigos modelo en el ámbito procesal: el Código Procesal Civil Modelo para Iberoamérica (1988), el Código Procesal Penal Modelo para Iberoamérica (1989) y el Código Modelo de Procesos Colectivos para Iberoamérica (2004). Puede accederse a sus textos en el siguiente enlace: http://www.iibdp.org/es/codigos-modelo/

${ }^{16}$ Según la rule 162, las sentencias definitivas sobre el fondo serán provisionalmente ejecutivas a pesar de que hayan sido recurridas, salvo que se disponga lo contrario en casos especiales. El apelante podrá instar la suspensión de la ejecución si demuestra que la ejecución resulta «manifiestamente excesiva». En tal caso, podrá supeditarse a la constitución de una caución tanto la suspensión de la ejecución provisional como su prosecución -variando, en consecuencia, la parte que habrá de cargar con la caución.
} 
las diversas tradiciones procesales nacionales; su incorporación a las European Rules habría comportado un retraso excesivo en la elaboración del proyecto y, posiblemente, habría resultado muy improbable alcanzar un nivel de detalle en la propuesta de regulación equivalente al que se ha logrado en general.

13. b) Tampoco se han incluido normas de jurisdicción y competencia. La previa existencia del sistema de competencia internacional uniforme establecido por el Reglamento Bruselas I bis hacía ocioso duplicar esfuerzos: en los Estados miembros de la UE estas reglas están vigentes; y respecto de los demás cumplen por sí mismas el papel de reglas modelo. Descender al terreno de las normas de jurisdicción por razón de la materia y de competencia objetiva, en cambio, habría sido inviable sin entrar en el terreno de la organización judicial, algo que superaría en exceso el ámbito del proyecto: puede ser razonable efectuar propuestas acerca de la mejor forma de organizar un sistema interno de tribunales de justicia, pero probablemente habría que hacerlo también desde el plano de la gobernanza y de la gestión pública, y no solo desde el ámbito estrictamente procesal. En cuanto a las normas de competencia territorial, su omisión se explica por los dos factores anteriores: muchas de las reglas de competencia internacional del RB I bis funcionan también como normas de competencia territorial interna; y, en todo caso, la distribución de asuntos entre los tribunales se encuentra fuertemente condicionada por la organización judicial interna.

14. c) La existencia de un acquis communautaire explica también que las European Rules no cuenten con un proceso monitorio ni con un proceso especial para los asuntos de escasa cuantía. El proceso monitorio europeo del Reglamento 1896/2006 es ya una realidad común para los Estados miembros de la UE y sirve como modelo para los que no lo son. Y lo mismo cabe decir del proceso europeo de escasa cuantía establecido en el Reglamento 861/2007. No habría tenido sentido que las European Rules se solaparan con normas ya existentes y vinculantes, que cabe suponer el resultado de un esfuerzo normativo equivalente al que subyace a aquellas.

Este solapamiento, de forma tal vez inesperada, sí que se ha producido en relación con los litigios colectivos, a los que se dedican con bastante detenimiento las rules 204 a 238. Cuando se decidió extender el proyecto a este tipo de procesos el acervo comunitario sobre esta materia lo integraban únicamente la Directiva sobre acciones de cesación de $2009^{17}$ y la Recomendación de la Comisión de $2013^{18}$ : la posibilidad de que llegara a aprobarse una directiva de alcance más general, que abarcase también las acciones colectivas resarcitorias, era aún incierta. Las European Rules, sin embargo, se han aprobado apenas un par de meses antes que la Directiva sobre acciones de representación de 2020, ${ }^{19}$ en la que se ha plasmado el consenso posible de los Estados miembros sobre la materia ${ }^{20}$. Ocurre, de todos modos, que la Directiva apenas si ofrece indicaciones o pautas en materia procedimental-se centra primordialmente en la legitimación y en la accionabilidad colectiva-: las European Rules, por ello, conservan todo el valor como modelo para una posible implementación a nivel interno de los nuevos estándares europeos.

15. d) Finalmente, ha sido decisión deliberada excluir del proyecto cualquier regulación específica de los procesos en materia de derecho de familia. ${ }^{21}$ De nuevo han sido razones pragmáticas las que justifican esta exclusión: de un lado, la estrecha vinculación con un derecho material muy poco armoni-

${ }^{17}$ Directiva 2009/22/CE del Parlamento Europeo y del Consejo, de 23 de abril de 2009, relativa a las acciones de cesación en materia de protección de los intereses de los consumidores (Versión codificada) (DO L 110, 1.5.2009).

${ }^{18}$ Recomendación de la Comisión, de 11 de junio de 2013, sobre los principios comunes aplicables a los mecanismos de recurso colectivo de cesación o de indemnización en los Estados miembros en caso de violación de los derechos reconocidos por el Derecho de la Unión (DO L 201, 26.7.2013).

${ }^{19}$ Directiva (UE) 2020/1828 del Parlamento Europeo y el Consejo relativa a las acciones de representación para la protección de los intereses colectivos de los consumidores, y por la que se deroga la Directiva 2009/22/EC (DO L 409, 4.12.2020).

${ }^{20}$ Para un primer análisis, cfr. F. GASCón InCHAUSTI, «¿Hacia un modelo europeo de tutela colectiva?», Cuadernos de Derecho Transnacional (Octubre 2020) Vol. 12, No 2, pp. 1290-1323.

${ }^{21}$ De hecho, no solo el Derecho de familia se deja fuera del ámbito de las European Rules. La rule 1, que define su ámbito de aplicación, opta por ceñirlo a litigios civiles y mercantiles, con exclusión del estado y capacidad de las personas, los regímenes económicos matrimoniales -o situaciones asimiladas-, la insolvencia, la seguridad social, el arbitraje, los alimentos y las sucesiones y testamentos. 
zado; de otro, una vigencia diluida de los principios jurídico-técnicos clásicos del proceso civil -dispositivo y aportación de parte-, que habría obligado a recargar el texto de duplicidades, de excepciones y de reglas singulares, en perjuicio de la claridad y de la visibilidad del modelo mismo.

16. Al margen de las omisiones, las European Rules tampoco podrían considerarse como un auténtico código debido a su clara ausencia de detalle normativo. No cabe esperar en su articulado una regulación suficiente como para adecuar a ella de forma directa la tramitación de un proceso judicial: respecto de muchos aspectos y cuestiones se ofrecen soluciones y respuestas a cuestiones procesales complejas, pero no preceptos que las desarrollen o articulen procedimentalmente. Así, por ejemplo, en materia de partes, la rule 32 señala que el tribunal puede requerir en cualquier momento, a quien actúe en el proceso como representante de otro, que acredite su representación; y la rule 33 atribuye al tribunal la potestad de comprobar de oficio la capacidad para ser parte y la capacidad procesal de cualquier litigante. Pero no se establece cauce procedimental para activar dichas potestades, ni el modo concreto en que la parte y la contraparte podrán presentar alegaciones, o el tipo de resolución que habrá de dictar el tribunal si considera que concurre alguno de los defectos procesales en cuestión.

17. Este esquema regulatorio genérico es una constante de las European Rules. Y es que una eventual aceptación de las Rules requerirá en todo caso de una suerte de transposición, similar a la que reclaman las directivas europeas, pensada precisamente para adaptarlas al concreto ecosistema judicial y procesal del país que las quiera usar de guía o modelo.

\section{Las European Rules of Civil Procedure sí ofrecen un modelo}

18. Ahora bien, aunque no sean -ni pretendan ser- un genuino código, las European Rules sí que son un auténtico modelo, cerrado y sistemático, de proceso civil de declaración y, en alguna medida, de «parte general»o «teoría general» del proceso civil. En el epígrafe siguiente se desgranarán sus elementos más característicos, pero es importante incidir ahora en dos extremos.

\section{A) El método y el enfoque seguidos para la elaboración de las European Rules}

19. Como ya se ha apuntado antes, UNIDROIT y ELI han dejado claro, al modificar su denominación en el trámite final de su aprobación, que ofrecen con las European Rules un modelo de proceso civil, que pueda ser utilizado (i) por los legisladores nacionales a la hora de abordar reformas de sus sistemas internos y (ii) por el legislador europeo, para el caso de que decida afrontar una armonización de los procesos civiles nacionales ${ }^{22}$. Y se atreven estas entidades a ofrecer estas reglas como modelo teniendo en cuenta el enfoque que se ha seguido para su elaboración: sobre la base de unos trabajos comparados, que han tenido en cuenta los ordenamientos nacionales, la normativa europea ya existente, la jurisprudencia del Tribunal de Justicia y la doctrina del Tribunal Europeo de Derechos Humanos, se ha querido presentar la mejor solución a las diversas cuestiones problemáticas a que se enfrenta cualquier legislador a la hora de diseñar un proceso civil justo y eficiente (lo que, en terminología inglesa, se conoce como best practice o best rule approach ${ }^{23}$.

20. En efecto, aspirar a ofrecer reglas modelo o best rules supone asumir que un mismo problema puede afrontarse de maneras diversas y requiere determinar cuál es preferible, tanto desde un punto de vista de funcionamiento interno, como también de cara a una posible armonización futura.

\footnotetext{
${ }^{22}$ Sobre esto, cfr. F. Gascón Inchausti, Derecho europeo y legislación procesal civil nacional: entre autonomía y armonización, Ed. Marcial Pons, Madrid-Barcelona-Buenos Aires-Sao Paulo, 2018.

${ }^{23}$ Cfr. G. Cuniberti, "The Promotion of Best Practices in European Civil Procedure: Some Initial Remarks", en B. Hess / X. Kramer (eds.), From common rules to best practices in European Civil Procedure, cit., pp. 439-450.
} 
21. Este análisis únicamente es posible a partir de una investigación comparada, que permita identificar no solo las diversas opciones seguidas a nivel interno, sino también su rendimiento práctico, su efectividad real. Es necesario, asimismo, precisar si el buen funcionamiento de ciertos sistemas nacionales de justicia civil obedece primordialmente a sus reglas procesales o si es simplemente lo esperable en un contexto general de buena gobernanza y buena gestión de lo público, posiblemente asociada a una adecuada financiación y a una adecuada conciencia de su relevancia político-social. Por otro lado, tampoco puede ignorarse que, en no pocas ocasiones, las mejores soluciones se ven abocadas al fracaso o a resultados mediocres debido al mal funcionamiento del sistema, cuya mejora no se aborda de forma integral: en un entorno adecuado, sin duda, podrían producir un rendimiento mucho mayor. En definitiva, las mejores soluciones se detectan a partir del estudio y del análisis comparado acerca de la eficacia y el rendimiento práctico de las posibles soluciones en liza.

22. Puede imaginarse fácilmente que este enfoque ha complicado en parte el desarrollo del proyecto, pues no siempre resulta sencillo reconocer como «mejor» una solución normativa que no es la propia -especialmente para aquellos ordenamientos que ya han reformado o reformulado sus sistemas de justicia civil en fechas recientes. Y es que ofrecer reglas modelo o best rules siempre puede tener un efecto disruptivo en aquellos sistemas procesales cuyas normas y prácticas habituales difieran de las propuestas en las European Rules. Cabe pensar, al menos, en dos riesgos.

23. De un lado, por supuesto, hay que contar con la posibilidad de que los «lectores» de ciertos ordenamientos se sientan en alguna medida «ofendidos»o «ninguneados» por las elecciones efectuadas. Se trata de un riesgo inevitable, pero tiene fácil remedio: si un legislador nacional considera que su sistema funciona adecuadamente, le ha de bastar con mantenerlo y no seguir el modelo que le ofrecen las European Rules.

24. También puede suceder que ciertas opciones se consideren incompatibles con la «cultura procesal» de un determinado país, con su arquitectura procesal y judicial, incluso desde un punto de vista constitucional. La solución, sin embargo, vuelve a ser la misma: estamos ante un instrumento de soft law.

Un claro ejemplo lo ofrece el sistema de recursos frente a la sentencia dictada en segunda instancia: optar, como se hace, por limitar la recurribilidad de estas resoluciones se considera preferible (rule 172), ${ }^{24}$ aunque posiblemente desde una perspectiva italiana resulte inasumible, dado el rango constitucional en ese país del acceso a la Corte di Cassazione, según el artículo 111 de su Constitución. En otros casos, los equilibrios son posibles: así, frente a una admisión amplia del recurso de apelación frente a sentencias dictadas en primera instancia [rule 166(1)(a)], propia de los sistemas continentales, se da cabida también a la posibilidad de una permission to appeal, más conforme con la tradición de los sistemas de common law $[$ rule $166(1)(\mathrm{b}) \mathrm{y}(2)]$.

25. El enfoque seguido para elaborarlas, así como su naturaleza de herramienta de soft-law se convierten así en factores clave a la hora de permitir que las European Rules of Civil Procedure desempeñen de manera efectiva el papel de guía y modelo que se han propuesto cumplir.

\section{B) Las European Rules of Civil Procedure están diseñadas de manera sistemática}

26. En tanto que normas modelo, es claro que sus destinatarios pueden hacer de ellas el uso que consideren oportuno. Podrían, por ello, asumir solo una parte o soluciones aisladas, en una suerte de cherry picking: como se ha apuntado antes, puede utilizarse el modelo de procesos colectivos de la

\footnotetext{
${ }^{24}$ Según la rule 172, solo cabe recurrir una sentencia dictada tras un recurso de apelación si el recurso se considera necesario para (a) reaccionar frente a la vulneración de un derecho fundamental, (b) asegurar una aplicación uniforme de la ley, (c) resolver una cuestión fundamental que no se limite al caso en cuestión o (d) desarrollar el ordenamiento.
} 
Parte XI de las Rules; o pueden trasplantarse los mecanismos de notificaciones de la Parte VI; o el sistema de medidas provisionales y cautelares de la Parte $\mathrm{X}$-por poner ejemplos de sectores aparentemente completos y cerrados sobre sí mismos-. Se trataría de una opción legítima, sobre todo cuando, como se ha visto, los legisladores nacionales pueden seguir considerando que su solución propia -diversa a la de las European Rules - funciona mejor, al menos en su «ecosistema procesal interno». Pero este potencial uso parcial y fragmentario de las European Rules no puede empañar su carácter sistemático y su coherencia interna.

27. En efecto, las European Rules representan un modelo completo de proceso civil declarativo, cuyas piezas están interrelacionadas y pensadas para funcionar como un todo: el sistema alegatorio y probatorio está previsto para funcionar en una dinámica procedimental como la diseñada, asumiendo los roles y poderes recíprocos de jueces y partes, la gestión activa del procedimiento y una vigencia del principio dispositivo matizado por el principio de cooperación (rules 2 a 8). Las diversas reglas, por tanto, solo se entienden adecuadamente dentro de su propio sistema. Y, en consecuencia, las soluciones que en ellas se ofrecen solo pueden considerarse como las mejores y como modelos porque están pensadas para operar en ese conjunto sistemático que conforman como un todo.

28. Esto explica, igualmente, que en algunos aspectos las propias European Rules ofrezcan alternativas o soluciones que puedan encadenarse de forma subsidiaria. Las reglas sobre notificación, por ejemplo, permiten adoptar enfoques distintos en función del sistema de partida vigente en cada país y, en concreto, en función de si existen huissiers de justice o profesionales similares encargados de la práctica de los actos de comunicación a petición de las partes interesadas o si, por el contrario, estas labores siguen en manos de los tribunales. ${ }^{25}$ En materia probatoria, por seguir con los ejemplos, también suscitó controversia la extensión de los poderes del tribunal y, en concreto, la posibilidad de que se acordara de oficio la práctica de pruebas no propuestas por las partes. ${ }^{26}$ Las soluciones en el plano comparado son divergentes en función del país y una solución neutra y eficaz tampoco era factible, dada la diferente forma de entender el principio dispositivo y el de aportación de parte en relación con este punto concreto. Como «solución de compromiso» se ofrece una regla general -la proposición probatoria compete a las partes [rules 25 (1) y 92(1)]-, que admite dos modulaciones: en primer término, la facultad del tribunal de sugerir a las partes que completen su proposición probatoria [rules 25(3) y 92(2)]; y, de forma más excepcional, la potestad del tribunal de acordar de oficio la práctica de algún medio probatorio no pedido por ninguna parte [rules 25(3) y 92(3)].

29. Por otro lado, hay que insistir en que las European Rules of Civil Procedure contienen un modelo de proceso civil en sentido estricto: no es, en otros términos, una propuesta de proceso civil transfronterizo, como lo eran los ALI/UNIDROIT Principles of Transnational Civil Procedure de 2004; tampoco se ha tratado de proponer una suerte de proceso modelo europeo para asuntos transfronterizos, a modo de eventual generalización de la idea que subyace a la existencia del proceso monitorio europeo o del proceso europeo de escasa cuantía. El objetivo es diverso: mejorar la eficiencia de los sistemas de justicia civil nacionales, como base para un mejor funcionamiento del sistema económico y social. ${ }^{27}$ Eso explica que, en determinadas partes de las European Rules, además de reglas pensadas como ordinarias, se hayan incluido

\footnotetext{
${ }^{25}$ El mejor ejemplo es la rule 71, dedicada a definir a quién corresponde la responsabilidad en la práctica de los actos de comunicación y que comienza con la siguiente alternativa: "La responsabilidad en la práctica de los actos de comunicación corresponde al tribunal / a las partes". Esta disyuntiva se mantiene a lo largo de la regulación, de modo que, en función de la opción seguida en cada país, se escojan como modelo unas reglas u otras.

${ }^{26}$ En general, sobre las dificultades de llegar a soluciones de consenso en materia de prueba, cfr. N. TrocKER, "From ALI-UnIDROIT Principles to common European rules on access to information and evidence? A preliminary outlook and some suggestions", Uniform Law Review, Vol. 19, 2014, pp. 239-291.

${ }^{27}$ Este peso de la eficiencia en el diseño procedimental también es subrayado, entre otros, por A. Uzelac, "Harmonised Civil Procedure in a World of Structural Divergences? Lessons Learned from the CEPEJ Evaluations", en X.E. KRAMER / C.H. VAN RHEE (eds.), Civil Litigation in a Globalising World, cit., pp. 175-205, y por X. KRAMER, "The structure of civil proceedings and why it matters: exploratory observations on future ELI-UnIDRoIT European rules of civil procedure", Uniform Law Review, Vol. 19, 2014, pp. 218-238.
} 
reglas especiales para asuntos transfronterizos (así sucede en materia de partes, de notificaciones, de obtención de prueba en el extranjero, de medidas cautelares y de procesos colectivos). Lo transfronterizo, por tanto, es secundario, porque lo primordial es la regulación de base de cualquier tipo de proceso declarativo.

\section{EI modelo procesal civil que proponen las European Rules of Civil Procedure}

30. Las European Rules of Civil Procedure están integradas por 245 preceptos, divididos en doce partes: I. Disposiciones generales (rules 1 a 28); II. Partes (rules 29 a 46); III. Gestión del procedimiento (rules 47 a 50); IV. Comienzo del proceso (rules 51 a 60); V. Desarrollo del proceso hasta el juicio (rules 61 a 67); VI. Primera notificación y comunicaciones procesales (rules 68 a 86); VII. Acceso a información y prueba (rules 87 a 129); VIII. Sentencia, cosa juzgada y litispendencia (rules 130 a 152); IX. Medios de impugnación (rules 153 a 183); X. Medidas cautelares y provisionales (rules 184 a 203); XI. Procesos colectivos (rules 204 a 238); XII. Costas (rules 239 a 245).

31. No resulta posible en esta sede entrar en un análisis detallado de todas las reglas propuestas, pero sí que se puede esbozar cuáles son las piezas básicas del modelo procesal civil que se ha considerado como preferible, para que el lector se pueda formar una idea de las grandes decisiones de política legislativa sobre las que se asientan.

\section{Un modelo de proceso civil flexible, basado en las nociones de cooperación, de proporcionalidad y de gestión activa del procedimiento}

32. Las European Rules no aspiran a promover una revolución del proceso civil tal y como lo conocemos: no se aspira a su socialización, a su privatización, a su desjudicialización o a su contractualización a ultranza, por poner ejemplos de tendencias que están o han estado en boga. Pero tampoco se pretende un mantenimiento de un modelo anclado sin más en las claves sentadas por Franz Klein a finales del siglo XIX, sino que se asumen aquellos hitos en la evolución comparada que han comportado cambios a mejor, entre los que cabe mencionar ahora los siguientes: (i) la consagración en el código de los principios básicos del proceso, con la cooperación como eje central, que se hizo bien visible en el nouveau code procédure civile francés y sus principes directeurs du procès; (ii) la noción de gestión activa del procedimiento (case management), que se consagró como trending topic con la reforma Woolf y las nuevas Civil Procedure Rules inglesas; (iii) la vocación hacia la eficacia, la proporcionalidad y el reforzamiento del valor de la primera instancia, que caracterizó la reconstrucción de nuestro proceso civil con la LEC de 2000 y que ha guiado reformas nacionales posteriores en muchos otros países; o (iv) un sistema de recursos más racional, que conciba la apelación como una revisión de la primera instancia, más que como una segunda primera instancia, al que se adhirió a finales del siglo pasado el ordenamiento alemán y que ha sido la tendencia en códigos y reformas posteriores.

33. Partiendo, pues, de un proceso civil regido por los principios dispositivo y de aportación de parte (v.g., rules 21 y 23 y 24, 56), que reflejan el principio de autonomía de la voluntad de las partes, se apuesta por promover un enfoque más cooperativo, especialmente en la gestión procedimental y en la búsqueda de soluciones consensuadas a la controversia ${ }^{28}$. Resulta especialmente simbólico que las tres primeras reglas - una vez sentado el ámbito de actuación de las European Rules- se dediquen a plasmar el principio de cooperación: es deber de las partes, de sus abogados y del tribunal cooperar para promover una solución de la controversia justa, eficiente y lo más rápida posible (rule 2). Este deber de coope-

\footnotetext{
${ }^{28}$ Cfr. A. UzelaC, “Towards European Rules of Civil Procedure: Rethinking Procedural Obligations”, Hungarian Journal of Legal Studies, Vol. 58-1, 2017, pp. 3-18.; C.H. van RHEe, "Case Management in Europe: A Modern Approach to Civil Litigation”, International Journal of Procedural Law, 2018-1, pp. 65-84; C.H. vAN RHEE, "Towards Harmonised European Rules of Civil Procedure: Obligations of the Judge, the Parties and their Lawyers”, Access to Justice in Eastern Europe, 2020-1, pp. 6-33.
} 
ración, en cuanto incumbe a las partes y a sus abogados, se traduce en la necesidad de realizar intentos razonables de resolver el litigio de forma consensual, de contribuir al correcto desarrollo procedimental, de aportar hechos y pruebas, de contribuir a la determinación de los hechos y de las normas aplicables por parte del tribunal, así como a actuar conforme a la buena fe, evitando cualquier abuso procesal en sus relaciones con el tribunal y las demás partes (rule 3). Del lado del tribunal, el principio de cooperación le arroja el deber genérico de asumir una gestión activa y eficaz del procedimiento, siempre respetando el principio de igualdad y supervisando que las partes y sus abogados cumplan las reglas del juego (rule 4).

34. De esta noción de cooperación se pueden deducir, a su vez, tres tendencias que convergen a la hora de inspirar y explicar el modelo de las European Rules: flexibilidad procedimental y promoción de la solución consensual del litigio, a las que hay que sumar la noción de proporcionalidad, como criterio transversal inspirador de buena parte de las opciones.

\section{A) Flexibilidad procedimental}

35. De un lado, caracteriza a las European Rules of Civil Procedure una gran dosis de flexibilidad en lo procedimental. ${ }^{29}$ Esta flexibilidad se halla estrechamente vinculada con la gestión activa de los litigios (el tan traído y llevado case management) ${ }^{30}$, cuyo núcleo esencial se concentra en las rules 47 a 50 , que otorga un papel central al tribunal a la hora de promover, cuando sea necesaria, la adaptación del procedimiento a las exigencias del caso - en consonancia con la también omnipresente noción de proporcionalidad-. La rule 49, que condensa buena parte de las potestades del tribunal, es claramente expresiva de lo heterogéneas que pueden ser sus manifestaciones: invitar a las partes a resolver por sí mismas el litigio o parte del litigio, sirviéndose, cuando sea oportuno, de métodos alternativos de resolución de controversias; programar audiencias adicionales para resolver cuestiones procesales y/o incidentales; determinar el cauce procedimental más adecuado al caso; fijar un calendario procesal con los plazos para las diversas actuaciones de las partes; limitar en número y/o extensión los escritos de las partes; establecer el orden en que deben enjuiciarse determinadas cuestiones $y$, en su caso, decidir si procede acumular o separar procesos; programar audiencias ad hoc para resolver de modo preliminar acerca de cuestiones relativas a la jurisdicción, a medidas cautelares o provisionales o incluso sobre la prescripción o caducidad de las acciones; resolver acerca de los cambios necesarios para una adecuada defensa de las partes, las consecuencias sobre el procedimiento de un cambio de partes o de la intervención de terceros u otros sujetos; resolver acerca de posibles cambios en las alegaciones o las proposiciones probatorias de las partes, a resultas de las pretensiones formuladas de contrario; exigir la presencia en una audiencia de cualquier parte, sea en persona o a través de un representante que tenga debido conocimiento del asunto; abordar la disponibilidad, admisibilidad, forma, exhibición e intercambio de pruebas y, si resulta adecuado en función del momento, pronunciarse sobre la admisión de la prueba y ordenar la práctica probatoria. Se trata, para nuestra mentalidad, de una suerte de totum revolutum, que mezcla potestades que, en buena parte de los códigos procesales hoy vigentes, estarían dispersas a lo largo de su articulado. De hecho, también lo están en las propias European Rules, que no tiene reparos en resultar hasta cierto punto reiterativa (de modo que, v.g., las normas sobre gestión de la actividad probatoria, enunciadas en sede de case management, reaparecen -con mayor extensión- en la Parte VII, dedicada a la prueba).

36. Pero dedicar específicamente al case management una parte de las European Rules es claramente revelador de la importancia que se le quiere atribuir y, sobre todo, de la importancia que se atribu-

\footnotetext{
${ }^{29}$ Recuérdese que la apuesta por la flexibilidad ya impregnaba la Recomendación $n^{\circ} \mathrm{R}$ (84) 5 del Comité de Ministros del Consejo de Europea acerca de los Principios del proceso civil diseñados para mejorar el funcionamiento de la Justicia, adoptada el 28 de febrero de 1984.

${ }^{30}$ C.H. VAN RHEE, "The development of civil procedural law in twentieth-century Europe: from party autonomy to judicial case management and efficiency", Russian Yearbook on Civil Procedure \& Arbitration, 7-8, 2011, pp. 82-95; A. CABRAL, "New Trends and Perspectives on Case Management", International Journal of Procedural Law, 2018-1, pp. 10-36.
} 
ye al tribunal como impulsor de la flexibilidad y de la adaptación procedimentales: se deja claro así que un buen funcionamiento del proceso requiere una fuerte implicación del órgano jurisdiccional, más allá de las partes -algo obvio-, pero también más allá de la vigencia general de las reglas procedimentales ordinarias, con renuncia al dogma de su carácter imperativo. Tampoco se trata -y es importante subrayarlo- de sostener que cada litigio necesite su propio programa singular, pues la gestión sería entonces imposible: las European Rules sí que contienen el diseño de un plan procedimental ordinario, con sus hitos predeterminados y sus plazos. Pero aspiran a escapar de la rigidez procedimental, que puede ser inadecuada para casos complejos o para casos que, por cualquier otro motivo, necesitan un tratamiento singularizado en algún aspecto.

37. Esta flexibilidad, de hecho, no se deriva únicamente de la noción de case management de las rules 47 a 50, sino que se desprende de todo el texto. El ejemplo más claro, qué duda cabe, lo ofrecen los plazos: aunque estén predeterminados, las European Rules admiten con frecuencia extensiones, que concederá el tribunal a petición de alguna parte que aduzca un motivo válido. Así, por ejemplo, el plazo para contestar a la demanda será, de ordinario, de 30 días desde la primera notificación; sin embargo, cuando resulte oportuno, el tribunal estará facultado para acordar una extensión (cuya duración máxima no se establece) [rule 54(1)]. De forma parcialmente diversa, la rule 159(1) señala que la parte apelada habrá de presentar su escrito de respuesta al recurso en un plazo de dos meses, a no ser que el tribunal acuerde otra cosa: aquí, por tanto, cabe entender que también puede haber margen para una reducción del plazo (v.g., en asuntos de escasa envergadura o complejidad).

38. Al margen de la cuestión específica de los plazos, se advierten muestras claras de flexibilidad a lo largo del articulado de las European Rules. Un claro ejemplo se halla en la rule 51(3)(a), que establece el deber inicial de las partes, antes incluso de que comience formalmente el proceso, de tratar de evitarlo y, en su defecto, de cooperar en lograr un desarrollo proporcionado del procedimiento: en ese contexto, se permite que las partes elaboren un posible calendario de desarrollo del procedimiento (a possible timetable for proceedings), algo que abre la puerta a una definición por las partes de los tiempos del procedimiento. Y es que el consenso de las partes es, junto al deber general del juez de velar por la eficiencia y la proporcionalidad, una fuente adicional de flexibilización del proceso: según la rule 50(1), de hecho, si las partes están de acuerdo en el contenido de alguna medida de gestión del procedimiento (case management measure), el tribunal debe acordarla, salvo que exista una razón fundada para no hacerlo.

\section{B) Fomento de la solución consensual de la controversia}

39. El principio de cooperación lleva también aparejado el fomento de la solución consensual del litigio, siguiendo una tendencia de asociar proceso judicial y ADR que parece inevitable ${ }^{31}$ y que, debidamente gestionada, puede resultar muy beneficiosa. Las European Rules no abordan la regulación de

\footnotetext{
${ }^{31}$ Una combinación similar entre gestión flexible del proceso y promoción de la solución consensual se advierte también en los trabajos del Parlamento Europeo para introducir un nuevo «proceso europeo» para la resolución acelerada de litigios mercantiles (cfr. T. Evas, Expedited settlement of commercial disputes in the European Union European, Added Value Assessment, European Parliamentary Research Service, 2018, accesible en https://www.europarl.europa.eu/RegData/etudes/ STUD/2018/627120/EPRS_STU(2018)627120_EN.pdf) que han cristalizado en la Resolución del Parlamento Europeo, de 13 de diciembre de 2018, con recomendaciones destinadas a la Comisión sobre la resolución acelerada de litigios mercantiles [2018/2079(INL)], accesible en https://www.europarl.europa.eu/doceo/document/TA-8-2018-0519_ES.html. El «proceso civil acelerado europeo» sería un instrumento que, mutatis mutandis, jugaría para los litigios comerciales de envergadura un rol similar al que cumple el proceso europeo de escasa cuantía en su ámbito: sería un proceso voluntario y limitado a la resolución de litigios mercantiles de carácter transfronterizo, llamado a competir con los cauces procesales previstos en cada Estado miembro por el legislador nacional. Y, entre los rasgos que habrían de definirlo, se encuentran la exigencia a las partes de que preparen sus demandas minuciosamente antes de acudir a los órganos jurisdiccionales, en combinación con una preclusión temprana de la posibilidad de presentar nuevos hechos o nuevas pruebas ante el órgano jurisdiccional, así como el fomento de la resolución judicial y extrajudicial amistosa.
} 
los mecanismos de ADR, pero tampoco son ajenas a su existencia y a su interrelación con los sistemas de justicia civil.

40. De un lado, el principio de solución consensual del litigio se eleva a la categoría de principio general del proceso (rules 9 y 10), con implicaciones tanto para las partes como para el tribunal. Sobre las partes recae el deber de cooperar en la búsqueda de una solución consensual, sea total o parcial, tanto antes como durante el desarrollo del proceso [rule 9(1) y (4)]. Los abogados, asimismo, tienen el deber de informar a las partes acerca de los diversos métodos de ADR a su alcance -aunque ello pueda suponer que sus servicios dejen de ser necesarios- [rule 9(2)]. En cuanto al tribunal, su rol es igualmente significativo [rule (10)]: debe facilitar y, en su caso, fomentar los acuerdos; a tal fin, puede informar a las partes acerca de los métodos a su alcance para llegar a un acuerdo, puede recomendarles el uso de un método específico e incluso puede implicarse directamente para que las partes lleguen a un acuerdo; también le compete homologar o certificar un acuerdo alcanzado por las partes, tanto antes del proceso como durante su pendencia, que lo haga plenamente eficaz y ejecutivo (rule 141).

41. Las European Rules no llegan a prever como obligatorio un intento -fallido- de solución consensual del litigio como condición para la interposición de una demanda ${ }^{32}$. Sin embargo, la rule 51 sí que establece, bajo la rúbrica de "Pre-commencement procedural duties", el deber de las partes de promover una solución consensual de la controversia y, en su defecto, un desarrollo eficaz del proceso.

42. Una manifestación adicional, que también lo es de la flexibilidad procedimental antes aludida, se advierte en las rules 57 a 60 , que incorporan un mecanismo novedoso, la llamada "petición conjunta de proceso consensual" "33, en virtud del cual las partes, de común acuerdo, pueden formular una solicitud, vinculante para el tribunal, acerca del modo en que ha de desarrollarse el proceso: las partes describen en la petición inicial sus pretensiones y defensas, los extremos sobre los que se proyectan sus discrepancias y que han de ser resueltos por el tribunal, la concreta tutela que solicitan, así como los medios de prueba a su disposición para sostener sus alegaciones fácticas. Esta petición, de hecho, puede acompañarse de acuerdos de índole procesal, en aquellas materias sujetas a la disposición de las partes (como la competencia territorial del tribunal, la adopción de medidas provisionales o la publicidad de las audiencias). Que las partes sean capaces de llegar a formular una petición conjunta de proceso consensual obedecerá, con toda probabilidad, al desarrollo eficaz por su parte de actuaciones destinadas a lograr una solución pactada; aunque el resultado no haya sido pleno, las partes pueden con esta fórmula "ahorrarse" las etapas iniciales del proceso y colocar directamente al juez a las puertas de la fase decisoria.

\section{C) Proporcionalidad}

43. La proporcionalidad, vinculada a la noción de eficiencia, es una suerte de ingrediente de base del diseño procesal que efectúan las European Rules. Las rules 6 y 7 le otorgan también el rango de principio rector del proceso y arrojan sobre el tribunal, las partes y sus abogados el deber de procurarla. Obviamente, la proporcionalidad, en sí misma, es tan inobjetable como difícil de definir: la rule 5(2) se esfuerza por ofrecerle al tribunal algunos parámetros con los que calibrar en concreto cuál pueda ser la solución proporcional, aludiendo a la naturaleza, importancia y complejidad del caso concreto, en un contexto en que el tribunal debe velar, en general, por la buena administración de justicia. Con ello, en el fondo, se está reconociendo que la proporcionalidad puede acabar siendo un argumento en el que sostener decisiones, en lo procesal, que resulten aparentemente limitativas de los derechos de una de las partes, por considerar prevalente la posición de la contraria.

\footnotetext{
${ }^{32}$ Algo previsto en diversos ordenamientos nacionales, al menos para litigios en determinadas materias y que, de hecho, puede acabar incorporándose al nuestro si se convierte en norma vigente el Anteproyecto de Ley de Medidas de Eficiencia Procesal del Servicio Público de Justicia, aprobado el 15 de diciembre por el Consejo de Ministros.

${ }^{33} \mathrm{Se}$ trata de la joint application for party agreed proceedings, inspirada en la procédure par requête conjointe del derecho francés.
} 
El principio de proporcionalidad, por ejemplo, podría servir, bajo determinadas circunstancias, para justificar el rechazo a practicar una prueba si resultara excesivamente costosa o demorase demasiado el curso del proceso $^{34}$. De hecho, en sede de medidas de acceso a fuentes de prueba, la rule 102(1)(c) condiciona su concesión, entre otros extremos, a la exigencia de que la naturaleza y cantidad de las pruebas objeto de la petición resulte razonable y proporcionada, teniendo en cuenta los intereses legítimos de todas las partes y de terceros.

44. Las rules 7 y 8 extienden la noción de proporcionalidad al terreno de las costas y de las sanciones procesales; en estos contextos, en cambio, la proporcionalidad no se presenta como criterio que justifique la adopción de una decisión difícil, sino más bien como sinónimo de moderación y de mera prohibición de exceso.

\section{Una dinámica procedimental clásica}

45. La estructura procedimental diseñada no es excesivamente detallada, porque en este punto más que en ningún otro se hace visible el carácter de las European Rules como herramienta de soft law. Se trata, por otra parte, de una estructura poco sorprendente, que responde a la lógica ordinaria que mejor sirve al objetivo de colocar al tribunal en la mejor posición de dictar la mejor sentencia posible: se encadenan alegaciones iniciales escritas de las partes, actividad preparatoria del juicio y celebración del juicio para la práctica de pruebas.

\section{A) Primera instancia}

46. La fase inicial de alegaciones ha de desarrollarse por escrito (rule 18), a través de unos escritos de demanda (rules 52 y 53) y de contestación a la demanda (rule 54) a los que se exige un elevado nivel de exhaustividad y de precisión en la determinación de hechos y de pretensiones, así como en la identificación y en la aportación de pruebas preconstituidas. Se apuesta, en este sentido, por una exigencia de concentración de alegaciones y pretensiones, que lleva aparejada, en caso de incumplimiento, una preclusión sobre eventuales procesos ulteriores (rule 22). ${ }^{35}$ Se abre, no obstante, un portillo razonable para la formulación de modificaciones en pretensiones y defensas, siempre que se encuentren justificadas y no alteren el equilibrio procesal (rule 55: cabe pensar, singularmente, en adaptarse a los cambios de circunstancias sobrevenidos durante la pendencia del proceso).

47. A los escritos iniciales de alegación ha de seguir una actividad preparatoria del enjuiciamiento sobre el fondo, que ha de pivotar sobre la base, al menos, de una audiencia preliminar (rules 61 y 62), aunque nada impide que sean varias, si así lo aconseja la mejor gestión del procedimiento. El objetivo de esta(s) audiencia(s) es solventar posibles cuestiones procesales, tratar de llegar a una solución consensuada y, sobre todo, preparar adecuadamente la ulterior actividad probatoria.

48. Una vez que el tribunal considere que el asunto está "maduro" para su enjuiciamiento -es decir, que ha sido adecuadamente preparado-convocará a las partes para la celebración del juicio (rule 64), en el que se practicarán las pruebas que no se hayan efectuado con anterioridad y se formularán las conclusiones finales de las partes. Las European Rules apuestan por la oralidad, la inmediación y la concentración en la práctica probatoria (rules 64 y 97), aunque sin caer en un dogmatismo excesivo. Así, por ejemplo, se hacen concesiones a la recepción de testimonios escritos ${ }^{36}$ [rules 18(3), 115 y 117]

\footnotetext{
${ }^{34}$ En el contexto actual de dificultad económica y austeridad pública, se torna inevitable vincular proporcionalidad y eficiencia: entre los criterios relevantes para medir la proporcionalidad de una decisión deben tenerse en cuenta el factor coste y el factor tiempo.

${ }^{35} \mathrm{Al}$ lector español le resultará familiar, debido a su semejanza con el art. 400 LEC.

${ }^{36}$ Se prevén, en concreto, dos excepciones. De un lado, en virtud de la rule 115(1), el tribunal puede acordar, si así lo piden
} 
y a cierto nivel de dispersión en la práctica de pruebas: en este último sentido, se acaba de apuntar cómo la rule 64(4) recuerda que en el juicio se practicarán aquellas pruebas no efectuadas hasta entonces, al tiempo que las normas sobre case management también permiten actos de genuina práctica probatoria en la fase intermedia del proceso (cfr. rules 49(11)(b), 62(2) y 63(1) $]^{37}$.

49. No puede decirse, en definitiva, que la dinámica procedimental se adhiera de manera rígida al modelo germánico, que busca concentrar la actividad probatoria en una audiencia final (nuestro "juicio"): esa es la tendencia y es bien evidente; pero no llega a imponerse como modelo ineludible, posiblemente para evitar las reticencias de aquellos ordenamientos más apegados a la tradición francesa, en que la oralidad en la práctica probatoria tiene un valor más limitado y en los que la audiencia final tiene como objetivo primordial la formulación de conclusiones jurídicas.

50. En lo que sí que se aprecia la preferencia por uno de los modelos actualmente vigentes es en materia de rebeldía (rules 135 a 140). Frente a ordenamientos como el español o el italiano, que asocian a la rebeldía el valor de una oposición a la demanda, se ha optado por permitir que, a instancias del actor, se pueda emitir directamente una sentencia estimatoria de la demanda-siempre que lo pretendido sea conforme con el relato fáctico-jurídico ofrecido en ella-: se ha seguido con ello la praxis vigente en buena parte de los ordenamientos europeos, con el alemán y el francés a la cabeza.

\section{B) Recursos frente a la sentencia}

51. En materia de recursos, las European Rules se adhieren a las tendencias que, sin ser unánimes, se han ido convirtiendo en mayoritarias en gran parte de los sistemas nacionales. ${ }^{38}$

52. Así, se propone una segunda instancia muy abierta, concebida primordialmente como una revisión de la primera instancia -y no tanto como un nuevo juicio plenario-(rules 167 y 168). El recurso de apelación que abre la segunda instancia, además, tendrá carácter ordinario: en principio, y en sintonía con la praxis habitual en los sistemas continentales, se puede sostener con éxito el recurso alegando infracción de ley, incorrecta valoración de la prueba y/o infracción procesal grave o con incidencia potencial en el fallo [rule 169(1)].

53. Por el contrario, las European Rules se decantan por un acceso mucho más limitado al tercer nivel de enjuiciamiento, habitualmente residenciado en un Tribunal Supremo o Corte de casación: con arreglo a la rule 172(1), solo será admisible un ulterior recurso si resulta necesario para reparar la vulneración de un derecho fundamental, preservar la uniformidad de la ley, pronunciarse sobre una cuestión fundamental con repercusión más allá del litigio en cuestión o promover el desarrollo del ordenamiento.

las partes, que la prueba testifical se aporte inicialmente por escrito, con carácter previo a la audiencia en que deba declarar oralmente -y con la previsión de que dicho interrogatorio se limite a las preguntas formuladas por la contraparte o el tribunal-. Se trata de una opción razonable en casos de litigios complejos (v.g., en procesos colectivos). De otro lado, la rule 117 da cabida a lo que en los sistemas angloamericanos se conocen como affidavits: si el tribunal lo permite, una parte puede presentar la declaración jurada de un testigo en relación con hechos de relevancia para el proceso, a la que el tribunal puede atribuir el mismo valor que a un testimonio ofrecido oralmente ante él -aunque la contraparte puede igualmente solicitar la comparecencia personal de dicho testigo-. Debe tenerse en cuenta, no obstante, que no se trata de una facultad ofrecida abiertamente a las partes, sino que se halla sujeta al control previo del tribunal, que debería manejarla con caución.

${ }^{37}$ De forma especial, la rule 62(2) se centra en ciertas actividades que tienden a ser "preparatorias" de la prueba, pero que en varios casos, a la postre, pueden hacer innecesaria su práctica ulterior. En concreto, se prevé que el tribunal se encargue de ordenar la aportación y el intercambio recíproco de documentos, de solicitar a las partes la aportación de testimonios escritos, de designar un perito y/o de organizar reuniones entre el perito judicial y posibles peritos de parte, de solicitar información a terceros, incluidas autoridades públicas y de practicar un reconocimiento judicial de la prueba obrante en la causa.

${ }^{38}$ En general, cfr. C.A. Kern, "Harmonisation of the Rules on Judgments and Appeals in Europe: A Few Remarks from the Inside “, en F. Gascón Inchausti / B. Hess (eds.), The Future of the European Law of Civil Procedure. Coordination or Harmonisation?, cit., pp. 223-239. 
La defensa del ius litigatoris, por tanto, se convierte en instrumental en un sistema claramente nomofiláctico y jurisprudencial, en el que solo se discute sobre cuestiones jurídico-sustantivas o procesales, pero no sobre los hechos [rule 174(1)]. En cuanto a los efectos de las sentencias dictadas tras este segundo recurso, se propone como regla ordinaria la devolución del asunto al tribunal de apelación, salvo que el recurso se haya fundado en infracción de ley y el tribunal que conozca de él considere que dispone de todos los elementos para resolver el caso por sí mismo (rule 175).

54. En ambos niveles se regula -en términos novedosos, al menos para los lectores procedentes de un buen número de ordenamientos- la renuncia al derecho a recurrir, que puede ser incluso previa a que se haya dictado sentencia en la instancia anterior-salvo en asuntos de consumo-(rule 154).

\section{Herramientas accesorias para reforzar el derecho a la tutela judicial efectiva}

55. Las European Rules of Civil Procedure parten de la asunción de que el derecho a la tutela judicial efectiva no solo se satisface con un diseño procedimental eficiente de los procesos declarativos en primera instancia y de los recursos frente a la sentencia; puede ser precisa, además, la existencia de piezas adicionales o accesorias, cuyo adecuado tratamiento es igualmente crucial para un diseño procesal eficaz. Es lo que sucede, al menos, con el acceso a la información y las pruebas, con la tutela provisional o cautelar y con la tutela colectiva.

\section{A) Acceso a información en poder de las demás partes y de terceros}

56. El nivel de acceso a información y pruebas que permite un sistema procesal repercute sobre el tipo de pretensiones que acaban formulándose ante los tribunales: sin pruebas carece sentido de litigar, pero en ciertos ámbitos jurídicos las pruebas no están a disposición de quien las necesita, sino en poder de la contraparte o de terceros: un eventual rechazo de estos sujetos a facilitar la información o a exhibir fuentes de pruebas puede acabar convirtiéndose en una restricción del derecho a la tutela judicial efectiva.

57. Por eso, uno de los aspectos más difíciles, pero al mismo tiempo más novedosos de las $E u$ ropean Rules ha sido el de elaborar una suerte de "European way to discovery", que permita superar las dificultades a la hora de acceder a las pruebas en poder de la contraparte o de terceros, pero sin incurrir en los peligros y excesos asociados a esta herramienta en el modelo procesal civil estadounidense.$^{39} \mathrm{En}$ este punto, la legislación y la praxis cotidiana en los diversos Estados miembros son muy diferentes, también en lo que atañe al mayor o menor rigor a la hora de cumplir las órdenes judiciales o las solicitudes formuladas de contrario. El objetivo principal en este punto ha sido la creación de un sistema de normas, relativamente autónomo, inspirado en parte en las reglas sobre esta materia de la Directiva 2014/104 sobre acciones de daños derivados de infracciones a las normas sobre defensa de la competencia ${ }^{40}$. El núcleo del sistema son las órdenes de acceso a prueba (access to evidence orders, orders for access to evidence), que acordará el tribunal, antes o durante el proceso, ordenando a un sujeto -parte o tercero- la aportación de documentos, información u otras fuentes de prueba pertinentes ${ }^{41}$.

\footnotetext{
${ }^{39}$ Para más detalles, cfr. F. Gascón Inchausti / M. Stürner, «Access to Information and Evidence in the ELI/UNIDROIT European Rules on Civil Procedure: Some Fundamental Aspects», Uniform Law Review, Vol. 24, 2019, pp. 14-41.

${ }^{40}$ Directiva 2014/104/UE del Parlamento Europeo y del Consejo, de 26 de noviembre de 2014, relativa a determinadas normas por las que se rigen las acciones por daños en virtud del Derecho nacional, por infracciones del Derecho de la competencia de los Estados miembros y de la Unión Europea (DO L 349, 5.12.2014), especialmente los arts. 5 a 7. Cfr. E. Vallines García, "Harmonising Access to Information and Evidence: The Directives on Intellectual Property and Competition Damages", en F. GASCóN Inchausti / B. Hess (eds.), The Future of the European Law of Civil Procedure. Coordination or Harmonisation?, cit., pp. 123-160; F. GASCÓN INCHAUSTI, "El acceso a las fuentes de prueba en los procesos civiles por daños derivados de infracciones de las normas sobre defensa de la competencia”, La Ley Mercantil, núm. 38, 2017, pp. 1-18.

${ }^{41}$ La orden, eso sí, permitirá que el solicitante accede a información o pruebas, pero no significa por sí misma que aquellas
} 
58. El sistema se funda en dos ideas básicas, control judicial y proporcionalidad a la hora de decidir si una parte o un tercero pueden ser obligados a aportar información, documentos u otras fuentes probatorias. Se trata con ello de evitar cualquier automatismo, estableciendo fuertes exigencias a las partes y a los tribunales. Así, para que el tribunal acuerde una orden de acceso a pruebas deben cumplirse requisitos de necesidad (la prueba solicitada ha de ser necesaria para fijar la certeza de hechos relevantes en el proceso), subsidiariedad (el solicitante no ha de disponer de otra vía para acceder eficazmente a la prueba) ${ }^{42}$ y proporcionalidad (la naturaleza y el volumen de la prueba solicitada ha de ser razonable y proporcionada, teniendo en cuenta los intereses legítimos de las partes y de terceros) [cfr. rule 102(2)]. El solicitante, además, ha de asentar una suerte de fumus boni iuris acerca de lo fundado de su pretensión [rule 102(2)] y ha de presentar una petición que resulte lo más específica posible, esto es, que determine las concretas pruebas o categorías de prueba a las que pretende acceder, como forma de evitar las conocidas como fishing expeditions, es decir, las peticiones de información meramente prospectivas [rules 102(1) y 102(4)].

59. Al mismo tiempo, y como forma de conjurar otro de los peligros que se imputan a estas medidas, se establecen exigencias muy estrictas en materia de confidencialidad: en algunos casos, la confidencialidad será un límite a la eficacia de las órdenes de acceso a pruebas, pero en otros prevalecerá el derecho de acceso a la prueba. Corresponde al juez definir en concreto el resultado de ese juicio ponderativo, fundado en el principio de proporcionalidad; ahora bien, si la orden se concede, irá acompañada de una serie de exigencias destinadas a mantener la reserva de la información (rule 103), así como de sanciones graves en caso de incumplimiento (rule 104).

\section{B) Tutela cautelar}

60. Las European Rules también contienen un sistema de tutela provisional y cautelar avanzado, pensado para evitar los perjuicios que el desarrollo temporal del proceso pueda generar en la efectividad de la tutela pretendida. Los caracteres básicos de las normas sobre tutela cautelar no sorprenderán al lector familiarizado con nuestro sistema procesal civil, si se tienen en cuenta los siguientes extremos:

(i) Además de medidas cautelares estrictamente asegurativas se da cabida también a medidas anticipatorias -las European Rules las llaman regulatory measures-, especialmente idóneas en apoyo de procesos en que se pretenden condenas no dinerarias (rule 196).

(ii) No existe una lista cerrada de medidas cautelares -aunque sí se ofrecen ejemplos-, de modo que el tribunal habrá de adoptar, en cada caso, la medida que resulta proporcionada a la situación cautelable (rule 185); por eso mismo, es posible que el sujeto pasivo de la medida solicite su sustitución por una caución dineraria [rule 187(1)].

(iii) Su adopción está condicionada en todo caso a la existencia de una apariencia de buen derecho y de un peligro en la demora (rules 193, 197 y 199), así como a la constitución de una caución -que, sin embargo, no se prevé como ineludible [rule 187(2)]: nos hallamos, pues, ante una asunción clara de la doctrina clásica sobre los presupuestos de las medidas cautelares.

(iv) Será posible adoptarlas antes de la interposición de la demanda, en cuyo caso será necesario interponer aquella en un plazo razonablemente breve, que se propone de quince días (rule 188) ${ }^{43}$.

\footnotetext{
se incorporen al proceso: corresponderá al solicitante "convertir" la información o el elemento obtenido en un medio de prueba admisible en el proceso [rule 101(3)].

${ }^{42}$ De hecho, la parte a la que se ordena la aportación de información o de prueba puede "reconvenir" pidiendo al tribunal que la sustituya por una orden igualmente eficaz pero menos gravosa [rule 107(4)].

${ }^{43}$ En esto, de hecho, las European Rules han optado claramente por un sistema de instrumentalidad reforzada, pues la incoación en plazo del proceso sobre el fondo no queda a expensas de la voluntad del sujeto pasivo de la medida, sino que resulta necesaria. Si las medidas son anticipatorias, no obstante, será esperable que su concesión conduzca a algún tipo de negociación o transacción que convierta el proceso ulterior sobre el fondo en innecesario.
} 
(v) También se admite, si está justificada, su adopción inaudita altera parte, con el consiguiente derecho a formular oposición frente a la medida adoptada (rule 186).

(vi) El solicitante se hace responsable de los daños y perjuicios que las medidas hayan causado a la parte contraria, en caso de que finalmente estas sean alzadas sin que aquel haya obtenido sentencia favorable [rule 190(1)].

61. En cambio, puede que a ese mismo lector le resulten más chocantes los tres siguientes extremos:

(i) Las medidas de aseguramiento de pruebas se engloban en el catálogo de las medidas cautelares (rules 198 y 199): siguiendo en esto el modelo francés, se incluyen entre ellas también la anticipación probatoria y la designación judicial de un perito para que emita un dictamen en relación con una cuestión determinada.

(ii) El solicitante de la medida cautelar es responsable de los daños o gastos que el cumplimiento o ejecución de la medida haya causado a terceros [rule 190(2)]: se trata de una cuestión básica, que muchos ordenamientos no resuelven expresamente y cuya definición explícita constituye, desde luego, una mejora normativa -que sirve claramente de modelo para terminar de perfilar los modelos nacionales de tutela cautelar que, como el nuestro, no se pronuncian sobre este extremo.

(iii) Sobre todo -y esto es, posiblemente, lo más significativo- se da cabida a los mandatos provisionales de pago (rules 200 y 201). En este punto, las European Rules son bastante detalladas, pues su pretensión es generalizar -al ofrecerlas como modelo- este tipo de medidas satisfactivas, habituales en algunos países (piénsese, v.g., en el référé-provision francés o en el kort geding holandés). Por ello, no se limitan a señalar como posible que el tribunal conceda al demandante el derecho a obtener provisionalmente el pago de una cantidad de dinero, sino que:

- De un lado, se establecen unos criterios claros y exigentes para su obtención: ha de haber un fumus boni iuris cualificado, que incluye los casos en que el demandado ha reconocido extraprocesalmente su obligación; el solicitante ha de acreditar igualmente su necesidad urgente de recibir el pago, que ha de prevalecer sobre el perjuicio que dicho abono podría causar al demandado; y su concesión, de ordinario, ha de quedar supeditada a la constitución de una caución por parte del solicitante.

- De otro, se señala una exigencia procedimental mínima: su adopción no es posible inaudita parte debitoris.

\section{C) Tutela colectiva}

62. Las European Rules asumen que, en ciertas situaciones, la mejor manera de otorgar tutela a los derechos lesionados es a través de un proceso colectivo: esto es lo que sucede cuando una pluralidad de sujetos se han visto lesionados a resultas de un mismo hecho dañoso. No resulta preciso recordar ahora los incentivos, jurídicos, económicos y hasta psicológicos, que la existencia de procesos colectivos aportan para lograr una aplicación efectiva del ordenamiento en ciertas parcelas -notoriamente, el consumo. Las European Rules ofrecen en este punto a los legisladores nacionales un modelo de proceso colectivo diseñado a partir de la experiencia comparada, teniendo en cuenta las mejores prácticas y eludiendo cualquier tipo de prejuicio respecto del modelo de las class actions estadounidenses.

63. Ya se ha dicho antes que, en este punto, la aprobación de las European Rules se adelantó en apenas dos meses a la publicación en el DOUE de la Directiva 2020/1828 sobre acciones de representación. En algunos puntos, las European Rules y la Directiva no son plenamente compatibles. Es lo que sucede en relación con la legitimación, que la Directiva quiere restringir a ciertas entidades habilitadas 
por los Estados miembros, mientras que las European Rules también abren a los particulares que sean miembros del grupo de afectados por el hecho dañoso [rule 208(c)]. Pero, por lo demás, las European Rules sí que ofrecen algo en relación con lo cual la Directiva guarda completo silencio: un modelo bastante detallado de proceso colectivo. En esto, por tanto, las European Rules pueden servir de base para implementar un sistema eficaz de proceso colectivo ${ }^{44}$ para aquellos ordenamiento que quieran o deban hacer reformas legales, tal vez con ocasión de la transposición de la Directiva 20200/1828 o para extender este tipo de tutelas a ámbitos más allá del consumo.

64. Así, se prevé un contenido mínimo para la demanda que pretenda dar comienzo a un proceso colectivo, en la que se acredite la concurrencia de todos aquellos factores que justifiquen su desarrollo como tal (rule 210). La admisión de la demanda como colectiva no es automática, sino que está sujeta a un primer filtro judicial - una suerte de class certification-, para la comprobación de que concurren las exigencias establecidas y que, como puede imaginarse, consisten en la constatación de que todas las pretensiones derivan del mismo hecho dañoso, son similares en lo fáctico y lo jurídico y se resolverán de modo más eficiente en un proceso colectivo que a través de una acumulación de acciones individuales (rules 212 y 213). Se ha asumido, igualmente, que la tramitación de este tipo de procesos requiere de mecanismos y poderes especiales de gestión activa por parte del tribunal (rule 218). Entre ellos se incluye, de forma notoria, la potestad de decidir si el proceso se amoldará a los parámetros del modelo de adhesión (opt-in) o de exclusión (opt-out), en función de lo que parezca resultar más eficaz en función de las circunstancias del caso concreto -aunque, como regla, se muestra preferencia por el opt-in-(rules 215 y 216). En relación con el case management, asimismo, se prevén dos herramientas especialmente útiles: (i) la creación de un registro público electrónico y abierto, en el que se han de inscribir las acciones ejercitadas como colectivas, de modo que se evite una pluralidad de procesos derivados del mismo hecho dañoso (rule 211); y (ii) cada proceso colectivo se ha de tramitar sobre la base de una plataforma electrónica ad hoc, que sirva para la gestión del procedimiento y de las comunicaciones (rule 220). Por último, existe una regulación clara del contenido y eficacia de la sentencia, con la previsión de que con las cantidades objeto de condena se constituya un fondo, a partir del cual se distribuya a cada perjudicado la cantidad que le corresponda [rules 227, 228 y 238(2)].

65. Junto a lo anterior, existe un régimen bastante detallado de normas para la aprobación de transacciones colectivas, tanto para las alcanzadas durante la sustanciación de un proceso (rules 221 a 226) como para -siguiendo el modelo inicialmente diseñado por el legislador holandés- homologar una transacción colectiva alcanzada al margen de cualquier proceso judicial (rules 229 a 232).

\section{IV. ¿Perspectivas de futuro?}

66. Una vez culminado el proyecto y presentadas las European Rules of Civil Procedure, se suscita una cuestión obvia: ¿y ahora qué? Por supuesto, trabajos como el que el lector tiene ahora ante sus ojos evidencian el indudable impacto científico-académico: si ya se han publicado trabajos sobre las European Rules cuando estaban aún en proceso de elaboración, con mayor seguridad cabe suponer que aparecerán nuevos estudios y, singularmente, que las European Rules formarán parte de las referencias académicas imprescindibles en materia de proceso civil. Al fin y al cabo, les subyace un estudio comparado de enorme envergadura y representan, asimismo, una muestra del consenso que, sobre ciertas materias, se ha alcanzado entre especialistas de diversos países. No sorprenderá, en definitiva, que se usen como ejemplo o modelo en trabajos académicos, y que engrosen el listado de sistemas normativos a los que se haga referencia en estudios sobre aquellas materias cubiertas por ellas.

${ }^{44}$ De hecho, el modelo de proceso colectivo de las European Rules ha sido ya objeto de un estudio exhaustivo: cfr. A. STADLeR / E. Jeuland / V. Smith, Collective and Mass Litigation in Europe. Model Rules for Effective Dispute Resolution, Edward Elgar, Cheltenham, 2020. 
67. Por estas mismas razones, es también posible que las European Rules se acaben invocando o utilizando en contextos extraacadémicos: no sorprendería que las citen abogados en asuntos de interés sobre materias que susciten dudas interpretativas a nivel interno y en relación con las cuales se quiera mostrar cuál es el estado de la cuestión a nivel europeo. Lo mismo cabe esperar de tribunales nacionales que quieran reforzar ciertas decisiones o incluso ciertos overrulings sirviéndose del status quaestionis deducible de las European Rules; y quizá también pueda suceder lo mismo en ciertos tribunales supranacionales, acostumbrados a no tener complejos a la hora de incluir referencias doctrinales en sus resoluciones: no debería resultar chocante que, en el futuro, el Tribunal Europeo de Derechos Humanos pudiera usarlas para identificar el estándar o consenso común europeo en algún asunto sometido a su decisión o que, por seguir con los vaticinios, se las mencionara a los mismos efectos en las conclusiones de algún Abogado General del Tribunal de Justicia de la UE. En otros términos, cabe esperar que se sirvan de las European Rules aquellos a quienes convenga, por su contenido y alcance, para reforzar alegaciones, pretensiones, conclusiones o decisiones. No dejaría, eso sí, de ser una suerte de soft use, coherente con su naturaleza de soft law.

68. Lo anterior, que ya es muchísimo, podría tal vez percibirse como decepcionante para los impulsores de la iniciativa, pues supondría asumir para las European Rules of Civil Procedure un destino similar -algo mejor, quizá, pero similar- al que aguardó a los ALI/UNIDROIT Principles of Transnational Civil Procedure. Cabe confiar, sin embargo, en que esto no suceda y que las European Rules of Civil Procedure acaben teniendo una proyección práctica y real superior.

69. Ya se ha visto, antes que nada, que el proyecto para su elaboración se ha desarrollado de forma abierta, ante diversos observadores externos institucionales, que han contribuido con aportaciones puntuales. También ha despertado el interés del Parlamento Europeo, que ha mostrado una especial sensibilidad a la hora de explorar una posible armonización de los procesos civiles nacionales en la Unión Europea $^{45}$. Es previsible, con mayor razón, que estas referencias se mantengan en caso de que se retome la actividad normativa en esta dirección, no solo por parte del Parlamento, sino también de la Comisión. En definitiva, no resultaría sorprendente hallar referencias a las European Rules of Civil Procedure en futuros textos prelegislativos de las instituciones europeas en materia procesal civil, tanto si se plantea una armonización más horizontal, como si se elaboran ulteriores instrumentos sectoriales que incluyan algún tipo de armonización procesal de corte vertical.

70. $Y$ es que, sobre todo, pienso que tienen un valor singular desde el punto de vista de la armonización procesal civil en Europa -rectius, en la Unión Europea-. Y lo tienen porque su elaboración demuestra que, desde un punto de vista técnico, una armonización avanzada es factible: es posible, en otros términos, aspirar a una armonización que se articule a través de la formulación de reglas específicas y que, por ello, vaya más allá de la enunciación de meros principios o reglas generales, como ocurrió inicialmente con el "proyecto Storme" ${ }^{46}$ o, en fechas más recientes, con la propuesta de directiva del Parlamento Europeo de 2017. La aprobación de las European Rules of Civil Procedure es la culminación de un esfuerzo colectivo de detección de estándares comunes y, sobre todo, de propuesta de las mejores soluciones a las necesidades de una justicia civil eficiente. Las European Rules son la prueba de que es

\footnotetext{
${ }^{45}$ En este sentido, pueden verse diversos estudios elaborados sobre esta materia bajo los auspicios del Parlamento Europeo:, European Parliamentary Research Service, In-Depth Analysis (R. MAŃKO), Europeanisation of civil procedure. Towards common minimum standards?, PE 559.499 (Junio 2015); European Parliamentary Research Service, Study (M. TuliBACKA, M. Sanz, R. Blomeyer), Common minimum standards of civil procedure (European Added Value. Assessment. Annex I), PE 581.385 (Junio 2016) -este Estudio, de hecho, incluye numerosas referencias al Proyecto ELI/UNIDROIT-; European Parliamentary Research Service, In-Depth Analysis (B. Hess), Harmonized Rules and Minimum Standards in the European Law of Civil Procedure, PE 556.971 (Junio 2016),

${ }^{46} \mathrm{El}$ «Proyecto Storme», como se recordará, fue el primer intento de aproximación de los sistemas judiciales en Europa, confeccionado por un grupo de procesalistas europeos bajo la dirección del Prof. Marcel Storme. Condujo a la elaboración del esqueleto de una posible directiva que habría de armonizar elementos claves del proceso civil para facilitar la comprensión mutua y la circulación de resoluciones judiciales [cfr. M. Storme (ed.), Approximation of judiciary law in the European Union, Kluwer, 1994].
} 
posible elaborar regulaciones completas desde un punto de vista institucional que reflejen una visión común del proceso civil y de sus elementos estructurales, sin que resulte necesario entrar en detalles procedimentales: dejan sin argumentos a quienes tradicionalmente han sostenido que los procesos civiles nacionales son demasiado diferentes como para que resulte posible formular un conjunto de reglas que resulten aceptables para todos.

71. Es importante recordar, en este sentido, que armonizar no es uniformizar o unificar: se trata de lograr una mayor aproximación de los sistemas procesales, que genere un entorno de seguridad y certidumbre jurídica a los operadores jurídicas y que permita una mejor coordinación en los asuntos transfronterizos ${ }^{47}$. Imaginemos un escenario de máximo éxito para las European Rules of Civil Procedure, que las elevara a la condición de directiva europea: tras su implementación por los Estados miembros, los procesos civiles nacionales seguirían siendo diferentes y, en muchos puntos, podrían seguir siendo "fieles" a determinadas tradiciones cuya preservación se hubiera considerado positiva o necesaria. Pero, a pesar de sus diferentes formulaciones nacionales, los procesos civiles de cada Estado miembro se expresarían en un lenguaje común, que permitiría a cualquier operador jurídico sentirse en terreno conocido con independencia del foro en que debiera litigar.

72. Cuestión distinta es que, políticamente, se pueda o incluso se quiera avanzar de forma decidida en la senda de la armonización de los procesos civiles nacionales en Europa. Hacer vaticinios, en la coyuntura actual, se me antoja un ejercicio fútil. Es obvio que no habrá avances hasta que esa armonización no se considere necesaria, pues solo entonces estará igualmente justificado activar las competencias normativas de la Unión Europea que lo hagan posible. Es, por ello, más probable que en un futuro más próximo sigamos encontrando muestras de armonización vertical en sectores materiales determinados. Y sería deseable que, en uno u otro escenario, las European Rules of Civil Procedure cumplieran esa función de guía o modelo con la que han sido elaboradas, de modo que pudiera originarse en torno a ellas una suerte de "fuerza gravitatoria", similar a la que han generado las Federal Rules of Civil Procedure estadounidenses sobre la regulación procesal civil estatal".

\footnotetext{
${ }^{47}$ M. Tulibacka, "Europeanization of Civil Procedures: In Search of a Coherent Approach", Common Market Law Review, No 46 (2009), pp. 1527-1565; Z. Vernadaki, "Civil Procedure Harmonization in the EU: Unravelling the Policy Considerations”, Journal of Contemporary European Research, Vol. 9-2 (2013), pp. 297-312.
} 